\title{
LOS ESPACIOS URBANOS DE LA MISERIA EN ALGUNAS NOVELAS DEL SIGLO XIX. UNA ESTÉTICA DE LA VERDAD
}

\author{
Yvan LISSORGUES \\ Université de Toulouse- le Mirail \\ Es la primera vez que un novelista de los buenos habla de este Ma- \\ drid pobre, fétido, hambriento, humillado... \\ (Leopoldo Alas, a propósito de La desheredada, 1881)
}

\section{RESUMEN}

En la estela de L'Assommoir (1877) y a partir de La desheredada (1881), por primera vez en España, acceden a la representación literaria los espacios urbanos del bajo pueblo: los barrios de la miseria del Sur de Madrid (en La desheredada, Fortunata y Jacinta, Nazarín, Misericordia, La Busca, Mala Hierba,...), los espacios del «proletariado» urbano de Marineda (La Tribuna) o de Vetusta (La Regenta).

Además del precioso valor documental de estas representaciones de unas realidades hasta entonces ocultadas o idealizadas, se impone, según una ética totalizadora, una estética de la verdad que es una superación de la teoría de los niveles estilísticos que ignoraba lo bajo, por feo y por indigno del arte o lo relegaba al campo de lo cómico (comedia) o lo toleraba como contrapunto burlesco de lo grande (épica, tragedia).

En España, como en toda Europa, las obras naturalistas de la segunda mitad del siglo XIX, gracias al total ensanchamiento temático y al rigor puesto en la fidelidad de la pintura, rompen definitivamente esa jerarquía de los estilos y muestran que cualquier realidad, como la de los barrios urbanos de la miseria, puede ser objeto de representación artística.

Palabras claves: espacios urbanos - miseria - novela - naturalismo - niveles estilísticos - estética de la verdad - Pérez Galdós - Leopoldo Alas, Clarín - Emilia Pardo Bazan - Pío Baroja. 


\section{ABSTRACT}

In the wake of L'Assommoir (1877) and with the Spanish novel La desheredada (1881), the urban environment of indigent social classes is portrayed: for the first time in literature: the miserable districts of the south part of Madrid, the degraded urban districts of the workers in big cities become embedded in the literary landscape.

In addition to the enormous documentary value of these representations of realities which had previously been either occulted or idealised, these novels convey not only an ethical view but also a corresponding aesthetics of truth, an aesthetics which supersedes the theory of stylistic categories which deemed the realms of the ugly and the vulgar to be unworthy of art and hence completely ignored them.

In Spain and in the rest of Europe, the naturalists novels of the second half of the nineteenth century, which portray a wider scope of themes and a more rigorous and a more exact copy of real life, definitely break away with the hierarchy of convened styles and legitimately demonstrate that reality, should it be common or unaesthetic, is worthy of artistic representation.

Key words: urban districts and spaces - poverty - novel - naturalism - stylistic categories - aesthetics of truth- Pérez Galdós - Leopoldo Alas Clarín - Emilia Pardo Bazán - Pío Baroja.

\section{PUNTUALIZACIONES PREVIAS E INTRODUCCIÓN}

Efectivamente, en 1881, por primera vez en España, en La desheredada, acceden a la representación literaria los barrios bajos del Sur de Madrid, esos espacios extra-urbanos de la miseria. Es una verdadera revolución estética que dimana de una nueva concepción ética de la representación literaria de la realidad.

No se trata ahora de la miseria honrada de esos pobres de la novela costumbrista, que viven con dignidad su condición con la esperanza de ir en derechura a la gloria al pasar a mejor vida. Tampoco de la depurada miseria inodora en la que germinan recortadas virtudes y estereotipados defectos, blancas flores del bien o negras manchas del mal, como en el mundo folletinesco de Sue o de Izco. Ni siquiera la semi-miseria de esa pobre clase media que, por querer parecer más de lo que puede, padece hambre, se impone sacrificios en el ámbito de sus estrechos pisos de ciertos barrios de Madrid, de la Encimada de Vetusta o del barrio de la mediocracia fabril y pobre de Barcelona pintada en La Papallona de Narcis Oller.

Es la miseria real, la que puede ver y oler quien de verdad a ella se asoma, trasladándose a visitarla y a estudiarla, y la que puede pintar, con pluma o con pincel, el que se atreve a romper los cánones de la tradicional estética de la belleza, según la cual lo feo, lo maloliente, las cloacas y la basura y aun el 
dolor echado en espacio sucio, no son dignos de atención y representarlos puede ser considerado como un crimen de lesa-hermosura, como muestra el proceso de las «osadías» naturalistas instruido por Juan Valera a partir de su fundamental criterio estéico, según el cual la novela «debe pintar las cosas no como son, sino más bellas de lo que son», como escribe en el prólogo de 1875 a Pepita Jiménez (Véase también Valera, 1996).

Los espacios urbanos, poco descritos, de la supuesta miseria, aludida en la novela picaresca, redimida artísticamente por la habilidad y listeza del pícaro protagonista, o por el visible propósito moral del autor, no tienen la implacable verdad que sólo puede dar una intencional focalización en los aspectos tristes y malolientes de la realidad social y humana que no acceden a la representación literaria antes de que se imponga como natural el verismo de la estética naturalista. Diga lo que diga Pérez Galdós en su deseo de españolizar el naturalismo del siglo XIX, el «realismo» cervantino de la novela picaresca no llega a la atrevida pintura de la miseria aglutinada en los relegados barrios del Sur de Madrid, tal como él mismo los describe en La desheredada, Fortunata y Jacinta y Misericordia o como los pinta Baroja en La Busca y Mala Hierba, o como pinta Emilia Pardo Bazán el «barrio de arriba», espacio de los pobres, y la Fabrica de Tabacos de Marineda o como alude Clarín a los Campos del Sol de Vetusta y a la conquista por los proletarios del espacio burgués del Boulevard (Alas, 1884-1885: 349-352). Que quiera que no, es una nueva mirada la que se impone al novelista consciente de la realidad social de su tiempo, consecuencia, más o menos fuerte, del moderno proceso de industrialización que aspira hacia la ciudad a los que huyen la miseria del campo, aun cuando se pinte lo que se ve con cierto humor o con latente deseo de redención.

Uno de los principios fundamentales de la estética naturalista es la integración de la teoría de Taine, según la cual hay una estrecha relación entre el hombre y el medio en que vive, idea que en el siglo XIX se impone al arte como natural. El espacio literario, rural o urbano, ya no puede ser el cuadro localista de la acción humana, tampoco el decorado romántico, placentero u hostil, tampoco el negro espacio de terror fabricado de la novela gótica. Ahora se impone la crudeza de la realidad; el mismo sol calienta el palacio del aristócrata y el tugurio del miserable. La diferencia es social y se graba en el espacio urbano: es lo que se intenta demostrar en las páginas que siguen.

Al hablar de naturalismo, en España y también en Francia, hay que entender dos cosas: por una parte, la doctrina teorizada por Zola por los años de 1880 en La novela experimental, (Zola, 1971; Zola, 1989) y que abre en España un debate polémico en el Ateneo y en la prensa (Véase, por ejemplo: Lissorgues, 1998: 19-31) y, por otra, las novelas de los Goncourt, del mismo Zola y de sus seguidores, sin olvidar las de Flaubert y de Balzac. Si el debate en 
torno a la teoría, ya bien conocido, es interesante y es importante al nivel de las ideas, influye menos en el quehacer de los novelista que el ejemplo de las mismas obras que alimentan el fructífero «coloquio de los novelistas», según la acertada expresión de Stephen Gilman. El impacto en Galdós, Clarín, Emilia Pardo Bazán y etc., de Germinie Lacerteux (1865) de los hermanos Goncourt y sobre todo de L'Assommoir (1877) de Zola es, por lo que se refiere a la superación de los niveles estilísticos tan bien estudiados por Eric Auerbach (Auerbach, [1946], 1968), es decir a la deliberada representación artística del bajo pueblo y de las espacios urbanos de la miseria, es mucho más determinante que el ruidoso debate en torno a la teoría naturalista, que por lo demás es posterior a la influencia directa de las novelas antes citadas.

L'Assommoir es en 1877 la primera novela que se atreve a pintar en toda su real realidad nauseabunda el bajo mundo de la miseria del barrio popular de la Goutte d'Or (Solda, 1997: 175-190), casi en las afueras de la gran urbe parisina. «Es la primera novela sobre el pueblo, novela que no miente y que tiene el olor del pueblo», escribe en el prefacio el autor que, en los apuntes de la encuesta emprendida previamente presenta así el tema:

Mostrar al pueblo en su medio, y explicar por este medio las costumbres del pueblo; mostrar cómo en París, la borrachera, la desbandada de la familia, las palizas, la aceptación de todas las vergüenzas y de todas las miserias se deben a las condiciones mismas de la existencia obrera, de los trabajos duros, de las promiscuidades, etc. En una palabra, un cuadro exacto de la vida del pueblo con sus basuras, su vida relajada, su lenguaje grosero. [...] Un cuadro espantoso que en sí trae su moralidad (Pagès, 2002, 251)

Adviértase que traducir L'Assommoir, rótulo de la taberna donde en el barrio se destila y se despacha aguardiente, por el neutral La taberna falsea el significado exacto del título de la novela, cuyo sentido se acerca más a matadero, a algo que acogota...

Enorme es el escandaloso éxito de esta séptima novela de la serie de Los Rougon, tachada por los fariseos puristas de la belleza de «sucia», «maloliente», «pornográfica», pero cuya originalidad sabe encarecer el mismo Mallarmé: «Tenemos aquí una grande obra; y digna de una época en que la verdad toma la forma popular de la belleza»; y el gran poeta simbolista subraya «la admirable obra lingüística que permite a tantos ineptos modos de expresión fraguados por pobres diablos tomar el valor de las más bellas fórmulas literarias, ya que consiguen hacernos sonreír o casi llorar» (Pagès, 2002, 254).

Parecidas reacciones suscita esta novela en España y aunque leída probablemente en francés por nuestros novelistas, su éxito impone una primera apresurada y aligerada traducción en 1878 publicada por Carlos Hierro (Saillard, 1997, 101). 
En la estela de La taberna (!), irrumpen en España, como se ha dicho atrás, los barrios pobres y fabriles a partir de La desheredada, en Fortunata y Jacinta, La Tribuna, La Regenta, Misericordia, La Busca, de pasada también en Nazarín y por lo que hace al pueblo trabajador (de Almadén) en La espuma de Palacio Valdés (Palacio Valdés, [1890], 1990). En eso ha de medirse más que en la fantasmática teoría naturalista, la verdadera influencia de Zola, el «poeta de la realidad», según calificativo de Clarín.

Dos observaciones para terminar esta larga y necesaria puntualización.

Para escribir la novela realista de la verdad, no basta la imaginación. Es preciso un buen conocimiento de la realidad. El primer trabajo del novelista es una observación precisa, hasta una encuesta de terreno emprendida en los espacios urbanos de la miseria poco familiares al escritor que vive en la parte «decente» de la ciudad, Madrid, La Coruña, Oviedo, etc. De interés son las confidencias acerca de estas experiencias de «observaciones y estudios directos del natural» que nos deparan algunos novelistas, Zola, Galdós, doña Emilia,... Y, dicho sea casi de paso, son pocos los escritores que, en aquella época, se atreven a pasar la frontera que separa los espacios urbanos «decentes» de la corte de los de la miseria. El más atrevido de los cuarenta autores, cuyos artículos ha reunido Eusebio Blasco en su, por lo demás interesante, Madrid por dentro y por fuera (Blasco, [1873], 2008), llega hasta el Rastro y lo de más abajo que lo parta un rayo. Del «Madrid humilde y popular», como muy bien sintetiza María Ángeles Ayala, sólo tienen carta de naturaleza los acostumbrados tipos, el mendigo, el aguador, la prostituta, algunos de los cuales, es de suponer, suben a diario de los barrios del Sur que nadie conoce (Ayala, 2008: 44-46).

Notable diferencia hay entre L'Assommoir y las novelas españolas citadas. El espacio urbano de la primera es únicamente el del barrio de La Goutte d'Or del cual no se sale nunca, salvo una vez para seguir la grotesca excursión de la boda de Gervasia y Coupeau al Museo de Le Louvre. Mientras que se descubren los barrios de la miseria de Madrid, Marineda o Vetusta, siguiendo a los protagonistas, entre los cuales sólo viven allí Amparo de La Tribuna y el joven Manuel de La Busca y de Mala Hierba. El narrador de La desheredada, de Fortunata y Jacinta, de Misericordia acompaña a Isidora Rufete, a Guillermina y Jacinta, a Benina, en unas ocasionales «visitas al cuarto estado», narradas según una doble mirada, la del personaje y la del narrador. Lo mismo en Vetusta, cuando Ana Ozores y el discreto narrador dejan la Fuente de Mari Pepa y se encuentran en El Boulevard con la multitud de operarios (Alas [1884], 1981, 349-353). Es que la caraterística común a todos los espacios urbanos 
de la pobreza es su relegación en las afueras; el barrio de la Goutte-d'Or, por ejemplo, está en la frontera que separa la ciudad del campo...

También es de advertir que si se puede sacar del tejido novelesco unos mapas objetivos, más o menos precisos de los espacios de la miseria de las respectivas ciudades, la representación literaria de cada espacio real es siempre el resultado, como afirma Clarín, de «la finalidad del artista y de su conciencia y habilidad» (Beser, 1972, 121), pues la novela es «un trozo de vida visto por un temperamento», como confiesa el mismo Zola.

\section{«OBSERVACIONES Y ESTUDIOS DIRECTOS DEL NATURAL»}

Es de sobra conocido el escrupuloso método de trabajo de Émile Zola. Cada novela es resultado de una previa preparación cuyos resultados (esbozos, planes, fichas de personajes, apuntes de encuestas en el terreno, etc.) se conservan en sendas carpetas en la Bibliothèque Nationale de París y en otras bibliotecas (Pagès, 2002, 186). Por lo que se refiere al tema de los espacios urbanos en L'Assommoir, son de interés los apuntes de la encuesta emprendida en el otoño de 1875 en el barrio de la Goutte-d'Or en los que se dibujan los sitios que serán los de la novela: la taberna con su alambique que permite servir caliente el orujo, el lavadero público, la fragua, la casa de vecindad en la que se apiñan las miserables familias y donde se encuentran improvisados talleres, los patios llenos de niños harapientos, etc.

Ningún novelista español ha dejado apuntes preparatorios de sus novelas, pero algunos han confesado en textos ocasionales, prólogos o cartas, que ellos también han tenido que explorar unos espacio urbanos que no suelen frecuentar, como, para Galdós, los barrios del Sur de Madrid o el Barrio de Arriba y la Fábrica de Tabacos de Marineda, nombre ficticio de La Coruña, ciudad natal de doña Emilia. Ocurre también que por haber vivido muchos años en una ciuadad de reducidas dimensiones, el novelista conoce y domina perfectamente todos sus espacios, hasta tal punto que el paisaje urbano al hacerse paisaje interior puede describirse según una especie de memoria imaginativa. Es el caso de Leopoldo Alas, que sin necesidad de mapa o de apuntes de encuestas, puede poéticamente transmutar la realidad espacial de Oviedo en la realidad literaria de Vetusta. Es igualmente el caso de la Pardo Bazán por lo que hace al familiar espacio urbano de La Coruña; no necesita plano para dominar la topografía de La Coruña, ni para describir y animar las callejuelas estrechas del Barrio de Arriba, el Mercadillo, el paseo de La Filas o las majestuosas avenidas del Barrio de Abajo; Marineda es para ella un paisaje interior como Vetusta lo es para Clarín y hasta diremos como lo son las calles centricas de Madrid para el inveterado transeúnte que es Galdós. 
En cambio, la Fábrica de Tabacos de La Coruña, o los barrios del Sur de Madrid no son espacios familiares y para conocerlos en su realidad hay que acercarse a ellos, pasar la puerta de la Frábrica y observar o transitar por aquellas sucias callejuelas que serpentean hasta el Manzanares, mirando, escuchando, oliendo. Doña Emilia y Galdós hacen lo mismo que Zola: se ponen directamente en contacto con esas realidades que se suelen ocultar, por lo menos en las obras literarias. ¿ «Estética de la berza», como escupen los purista, adeptos de un arte depurado? No, jestética de la verdad! Y así, de pasada, lo confiesan doña Emilia y don Benito.

Aquélla evoca en una carta a Galdós y exagerando de seguro algún tanto, «los dos meses que pasé en la fábrica de tabacos, respirando nicotina» y recuerda «los insultos más o menos explícitos que por esta obra me dijeron» (insultos de los bien pensantes de España, hermanastros de los que en París, hicieron aspavientos ante L'Assommoir). Y añade la condesa, con cierta falsa modestia: «sólo como fiel trasunto de algunas escenas, calco y reproducción exacta de realidades humildes y vulgaridades psicológicas, puede interesar alguna que otra página de La tribuna» (Faus, 2003, I, 207). Otra media confesión de su paso por la Fábrica de Tabacos, figura en el relato La cigarrera, recientemente publicado por Santiago Díaz lage: «Si queréis saber cómo se hace el cigarro que fumáis, yo os lo referiré, tal cual lo he visto en mi patria, en La Coruña, habiendo tenido mil ocasiones de presenciarlo» (Díaz Lage, 2006: 372).

En el «Prefacio del autor escrito especialmente» en 1913 para una edición en Francia de Misericordia (Pérez Galdós, 1951, 5-9) revela Galdós su difícil exploración de los miserables barrios del Sur de Madrid. Es un documento de gran interés social, antropológico y literario, que, de seguro, le hubiera interesado a Baroja cuando escribió en 1904 La Busca (primera novela de la trilogía La lucha por la vida) o las dos siguientes, Mala Hierba y Aurora Roja. Es un documento tan importante que, en este estudio de los espacios urbanos de la miseria, merece, aunque largo, transcripción completa de la parte relativa a dichos espacios.

En Misericordia me propuse descender a las capas ínfimas de la sociedad matritense, describiendo y presentando los tipos más humildes, la suma pobreza, la mendicidad profesional, la vagancia viciosa, la miseria dolorosa casi siempre, en algunos casos picaresca o criminal y merecedora de corrección. Para esto hube de emplear largos meses en observaciones y estudios directos del natural, visitando las guaridas de gente mísera o maleante que se alberga en los populosos barrios de Sur de Madrid. Acompañado de policías escudriñé las Casas de dormir de las calles del Mediodía Grande y del Bastero, y para penetrar en las repugnantes viviendas donde celebran sus ritos nauseabundos 
los más rebajados prosélitos de Baco y Venus, tuve que disfrazarme de médico de la Higiene Municipal. No me bastaba esto para observar los espectáculos más tristes de la degradación humana, y solicitando la amistad de algunos administradores de las casas que allí llamamos de corredor, donde hacinadas viven las familias del proletariado ínfimo, pude ver de cerca la pobreza honrada y los más desolados episodios del dolor y la abnegación en las capitales populosas. Años antes de este estudio había yo visitado en Londres los barrios de Whitechapel, Minories, y otros del remoto Este, próximo al Támesis. Entre aquella miseria y la del bajo Madrid, no sé cuál me parece peor. La de aquí es indudablemente más alegre por el espléndido sol que la ilumina.

Este testimonio parece eco amplificado y con acento moral patético de los fríos apuntes, de Zola, aludidos atrás, sobre el barrio de la Goutte-d'Or. En Madrid, Londres, París son realidades aquellos barrios de la miseria, realidades por primera vez estudiadas por novelistas artistas como objeto de representación literaria. Después de presentar al personaje del moro Almudena, figura también sacada del natural, sigue Galdós evocando otras facetas del espacio de la miseria del Sur de Madrid:

El afán de estudiarla [la figura del moro] intensivamente me llevó al barrio de las Injurias, polvoriento y desolado. En sus miserables casuchas, cercanas a la Fábrica del Gas, se alberga la pobretería más lastimosa. Desde allí, me lancé a Las Cambroneras, lugar de relativa amenidad a orillas del río Manzanares, donde tiene su asiento la población gitanesca, compuesta de personas y borricos en divertida sociedad, no exenta de peligro para el visitante. Las Cambroneras, la Estación de las Pulgas, la Puente segoviana, la opuesta orilla del manzanares hasta la casa llamada de Goya, donde el famoso pintor tuvo su taller, completaron mi estudio del bajo Madrid, inmenso filón de elementos pintorescos y de riqueza de lenguaje.

Este precioso documento merece varias observaciones.

El espacio urbano que en este precioso prólogo evoca Galdós es rigurosamente homotético del que describe en Misericordia y es tan real que se corresponde con el verdadero mapa artesanal de Madrid que de dicho documento y de las novelas estudiadas he sacado y que incluyo en este trabajo para que el estudioso lector pueda situar cada lugar evocado.

En el Prólogo de 1913, sólo es cuestión de Misericordia, novela publicada en 1897, pero esos mismos espacios del Sur de Madrid se recorren en parte en La desheredada (1881), en Fortunata y Jacinta (1887), en Nazarín (1895) y pueden localizarse en mi artesanal mapa. Es prueba de que el novelista había transitado antes por gran parte de aquellos barrios de la miseria, obeservándolos, estudiándolos.

Vamos a ver cómo describe Galdós en sus novelas esos reales espacios y cómo les da vida, pero no es inútil que antes le echemos una mirada a las 
ambiguas, por irónicas, palabras de Baroja que preceden (a modo de prólogo a un capítulo) en La Busca el inicio de la representación de esos mismos barrios.

El madrileño que alguna vez, por casualidad, se encuentra en los barrios pobres próximos al Manzanares, hállase sorprendido ante el espectáculo de miseria y sordidez, de tristeza e incultura que ofrecen las afueras de Madrid en sus rondas miserables, llenas de polvo en verano y de lodo en invierno. La corte es ciudad de contrastes; presenta luz fuerte al lado de sombra obscura; vida refinada, casi europea, en el centro, vida africana, de aduar, en los suburbios. Hace unos años, no muchos, cerca de la ronde de Segovia y del Campillo de Gil Imón, existía una casa de sospechoso aspecto y de no muy buena fama, a juzgar por el rumor público. El observador...

En este y otros párrafos de la misma calaña tenía yo alguna esperanza, porque daban a mi novela cierto aspecto fantasmagórico y misterioso; pero mis amigos me han convencido de que suprima tales párrafos, porque dicen que en una novela parisiense estarán bien, pero en una madrileña, no; y añaden, además, que aquí nadie extravía, ni aun queriendo; ni hay observadores, ni casas de sospechoso aspecto, ni nada. Yo, resignado, he suprimido esos párrafos, por los cuales esperaba llegar algún día a la Academia Española (Baroja, 1972: 59-60).

Dejando de lado los comentarios éticos y estéticos que estas palabras suscitan, pues cada uno puede hacérselos, me limito a subrayar que ese mundo que Baroja descubre «por casualidad» está ya pintado con pelos y señales en las novelas de Galdós, que por lo visto él no conoce... En ellas nos focalizamos ahora por lo que se refiere a Madrid, acudiendo a La Busca y a Mala Hierba, cuando venga al caso. Para los espacios urbanos de la pobreza en Marineda y Vetusta, tenemos La Tribuna y algunas páginas de La Regenta.

\section{RELEGACIÓN EN LAS AFUERAS DE LOS BARRIOS DE LA MISERIA}

Efectivamente, aparte en La tribuna, novela centrada en los barrios pobres de Marineda donde vive Amparo, joven obrera del pueblo alzada a protagonista, lo que le vale a la obra el privilegio de ser en España la primera novela «proletaria» (y añadiré la única) del siglo XIX, en las novelas de Galdós (como en La Regenta y en La espuma) los espacios de la miseria y del trabajo son como ventanas abiertas ocasionalmente a un mundo fuera de la normalidad aristocrática, burguesa o mesocrática que es la base social de la representación novelesca; su descripción en movimiento, se da como inciso narrativo, como digresión accidental, pero digresión de gran densidad, de gran peso de significación y de alto alcance ético y estético. 
Puede decirse que en La Tribuna y en La Regenta la estructura espacial de la ciudad, aunque homotética de la realidad de La Coruña y de Oviedo, tiene un carácter simbólico, más significativo aún en la primera.

En Marineda, tomando palabras de Marisa Sotelo, «La configuración de la ciudad, desde el barrio señorial de nobles casas de piedras blasonadas, donde habita la burguesía; el paseo de las Filas, centro neurálgico del ocio marinedino; la Pescadería, barrio humilde o el de Amparo, ya en los confines de la ciudad, de pobres casuchas y calles sin asfalto, donde juegan un montón de niños desnutridos y harapientos» (Sotelo, 2010: 34). La división del espacio urbano en dos partes, el barrio pobre de Arriba y el barrio rico de Abajo, separadas por el páramo de Solares (Pardo Bazán [1883], 2002: 71), es de implacable geometría, cuya representación gráfica, aunque somera y nada comparable con el mapa de los barrios del Sur de Madrid levantado gracias a la meticulosidad galdosiana, es altamente significativa de la separación de las clases sociales y del aislaimiento del barrio de Arriba, con sus callejas, como la de los Castros donde está la casucha de Amparo, el lavadero público, el Alto de Aguasanta y al oeste la Fábrica de Tabacos en la plaza de Palloza.

\section{Mapa de Marineda}

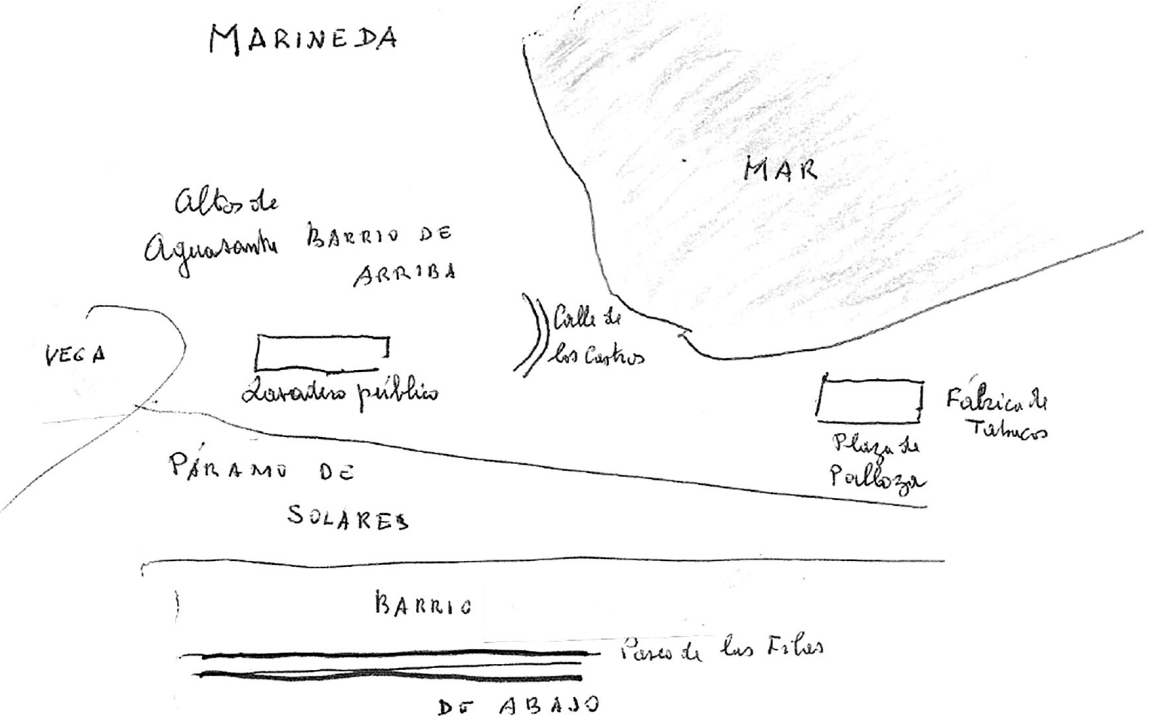


Parecido reparto clasista de la población ofrece Vetusta, en la que los obreros están relegados en el extrarradio, en esos Campos del Sol, «al sudeste, donde la Fábrica Vieja levantaba sus augustas chimeneas, en rededor de las cuales un pueblo obrero había surgido» (Alas [1884], 1981: 110). Con recelo mira el Magistral ese trozo de espacio urbano y lo apunta con su catalejo desde lo alto de la torre de la catedral: «Allí vivían los rebeldes; los trabajadores sucios, negros por el carbón y el hierro amasados con sudor». Ve con despecho «aquellas chimeneas delgadas, largas como monumentos de una idolatría» que se le parecen «parodias de las agujas de las iglesias» (Ibid., 113-114). Pero ningún personaje se da la molestia de penetrar en los Campos del Sol, ni el narrador encuentra ocasión para hacerle una visita a ese barrio... En cambio, son los obreros que se desbordan en el espacio de los «decentes»: cada tarde, al anochecer, a la hora en que dejan el trabajo, «costureras, chalequeras, planchadoras, ribeteadoras, cigarreras, fosforeras, y armeros, zapateros, sastres, carpinteros y hasta albañiles y canteros, sin contar otras muchas clases de industriales», toman posesión, como por asalto, de la Calle del Triunfo de 1836, también llamada El Boulevard (palabra curiosa que no parece vetustense; ¿será guiño del autor en alusión intertextal a alguna novela de Zola o algún cuadro de Monet?) ¡La fuerza del trabajo de mil brazos, saliendo como fuerte ola de su confinamiento espacial para derramarse por una porción de tierra ajena y sacudir la perezosa molicie improductiva del resto de Vetusta! Si es muy limitada en La Regenta la atención a los espacios pobres de los trabajadores, la fuerza y la pertinencia del símbolo que representa «la conquista del Boulevard», son de gran alcance histórico y literario (Ibid., 349-353).

No es un descubrimiento que exista en la realidad un repartimiento clasista del espacio urbano, pues lo enseña la Historia, pero es una novedad hasta cierto punto que la «novela burguesa» del siglo XIX reproduzca con fidelidad tal reparto y sobre todo que enfatice el aislamiento de los espacios de la pobreza. Un páramo separa el barrio de Arriba del de Abajo en Marineda. Recordemos las palabras de Baroja citadas atrás: «La corte es ciudad de contrastes; [...] vida refinada, casi europea, en el centro, vida africana, de aduar, en los suburbios». Con palabras fuertemente reprobatorias exclama el narrador de La desheredada al descubrir, siguiendo la mirada de Isidora, la miseria del barrio de Las Peñuelas: «Aquello no era aldea ni tampoco ciudad; era una piltrafa de capital, cortada y arrojada por vía de limpieza para que no corrompiera el centro» (Pérez Galdós, [1881], 1992: 38).

Gracias a las novelas de Galdós (y de Baroja) se puede transitar por aquellos barrios del Sur de Madrid, verlos vivir en su presente de ayer, observarlos, medir las capas de sus trabajos y miserias y hasta olerlos. Gracias a La Tribuna, 
sabemos cómo vivían en La Coruña unas mujeres del pueblo bajo, en aquellas casuchas alzadas a lo largo de populosas callejas empinadas y nos llega el sofocante ambiente de la Fábrica de Tabacos con la visión de las penosas faenas de cigarreras y cigarreros.

\section{«UNAS VISITAS AL CUARTO ESTADO»}

Este epígrafe es el título, pasado al plural, del capítulo IX de Fortunata y Jacinta. Estas visitas las puede hacer el lector siguiendo las andanzas por aquellos barrios del extrarradio madrileño de Isidora, de Guillermina y Jacinta, de Misericordia (Benina), de Manuel, personaje de La Busca y de Mala Hierba, a los que seguiremos efectivamente en este trabajo hasta que lleguen a sus metas. Sin embargo, para ir más allá del mero parafraseo, me otorgo el derecho de sintetizar a partir de cierto momento sus observaciones y las de los narradores que los acompañan. Así se evitan las repeticiones, así pueden reunirse las aportaciones de doña Emilia con las de Galdós y Baroja, y calibrar sus respectivos puntos de vista e iniciar una especie de tipología de la miseria urbana en las novelas del gran realismo del siglo XIX. Así pues, a cierto momento aparecerán los subtítulos siguientes: Casas de dormir, corralas o paradas; Esas callejuelas; Talleres y fábrícas; Niños de la basura; El lenguaje de los olvidados. (Así, debería salir un capitulillo de suma importancia: El lenguaje de los olvidados. No sale. Saldrá en otra ocasión.)

Tres caminos, según las novelas de Galdós y Baroja, permiten acceder a los barrios del Sur de Madrid: la calle de Embajadores, la de Toledo, la ronda de Segovia.

Isidora Rufete para llegar a la calle de Moratines en el barrio de las Peñuelas, donde viven ahora su tía Encarnación Guillén, la Sanguijuelera y su hermano Mariano, va por el «gigantesco paseo de Embajadores» (La desheredada, [1881], 1992: 36). A Guillermina y a Jacinta que van en busca de la Corrala situada entre la calle del Bastero y la de Mira el Río, les viene mejor transitar por la muy animada calle de Toledo (Fortunata, [1887], 1993: 180-182). El itinerario que sigue Manuel para ir desde la calle céntrica de Mesonero Romanos, donde trabaja su madre, hasta, para abreviar, esta misma Corrala de la calle de Mira el Río, que para él es el corralón o la casa del tío Rilo, es más complicado: va por Arenal, plaza de Oriente, el Viaducto, la ronde de Segovia: «veíase desde allá arriba el campo amarillento que se extendía hasta Getafe y Villaverde, y los cementerios de san Isidro con sus tapias grises y sus cipreses negros» (La busca, [1904], 1972, 61). Benina, por su parte, en sus frecuentes bajadas a los barrios del Sur desde la calle Imperial, donde esta el piso de su ama doña Paca, toma según las circunstancias, uno u otro de los tres caminos. 
Los barrios populosos del sur de Madrid

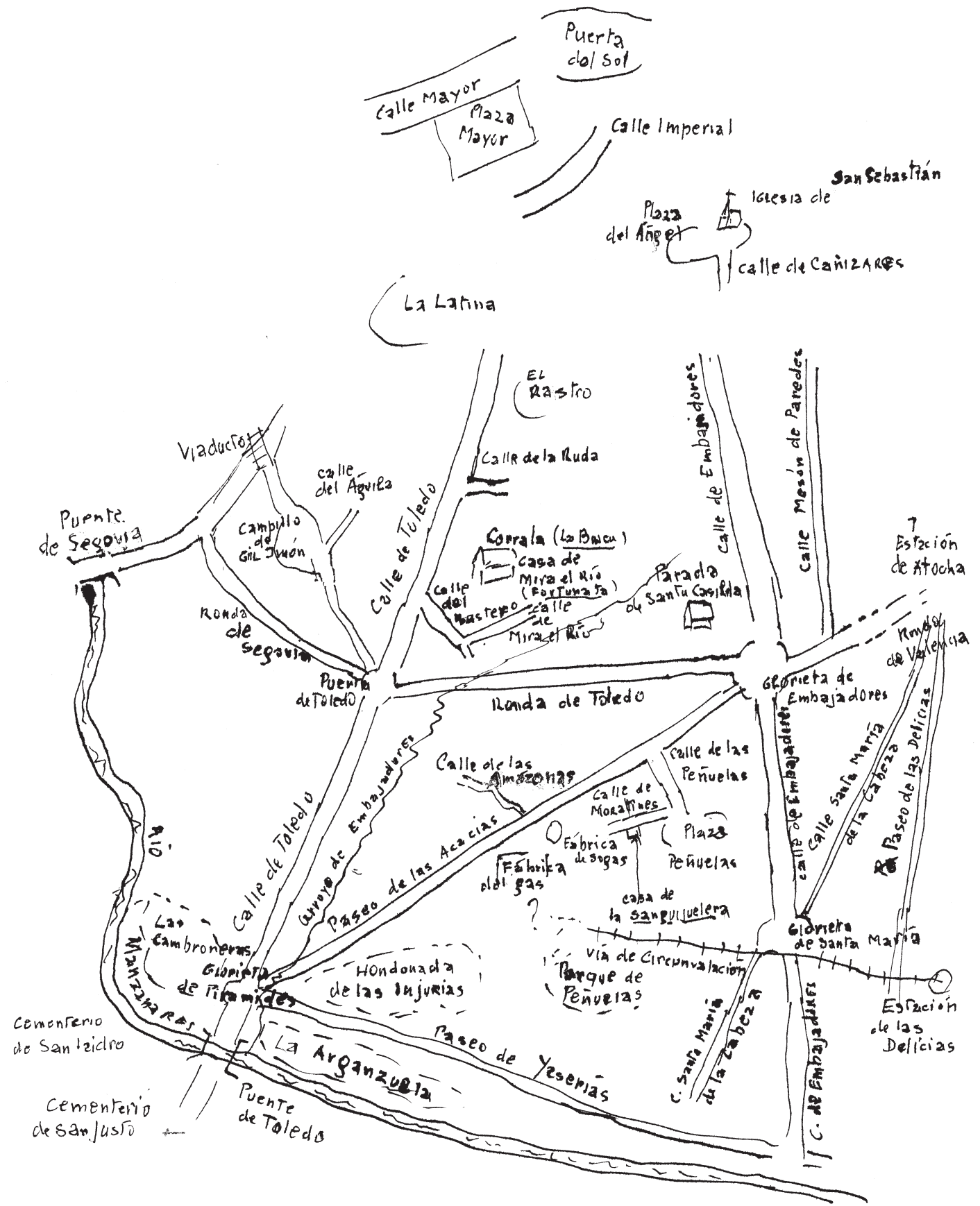


Isidora, después de atravesar la ronda Toledo, nota que el paseo de Embajadores «se convierte en despeñadero, rodeado de casuchas que parecen hechas con amasada ceniza» (La desheredada, 1992: 98) y al entrar en las Peñuelas le parece a ella, «que tiene el don de imaginar fuerte» (Ibid., 37), una ilusión lo que está viendo.

$\mathrm{Al}$ ver, pues, las miserables tiendas, las fachadas mezquinas y desconchadas, los letreros innobles, los rótulos de torcidas letras, los faroles de aceite amenazando caerse; al ver también que multitud de niños casi desnudos jugaban en el fango, amasándolo para hacer bolas y otros divertimientos; al oír el estrépito de machacar sartenes, los berridos de los pregones ininteligibles, el pisar fatigoso de bestias tirando de carros atascados y el susurro de los transeúntes, que al dar cada paso lo marcaban por una grosería, creyó por un momento que estaba en la caricatura de una ciudad hecha de cartón podrido (Ibid.).

Encuentra con sorpresa la Cacharrería de su tía. « Cómo había descendido la infeliz de grado en grado, desde su gran commercio de loza y sanguijuelas de la antigua calle del Cofre [...], hasta aquel miserable ajuar de cacharros ordinarios!» (Ibid., 39). Así nos dice Galdós, sin insistir, que los barrios del Sur recogen a las víctimas de la mala fortuna.

A partir de cierto momento, el narrador abandona a su personaje para curiosear por tan ínsolitos espacios y ve (lo que verrá Martín Santos, en 1961, en «las chabolas» de Tiempo de silencio):

Chozas, tinglados, construcciones que juntamente imitan el palomar y la pocilga, tienen su cimiento en el lodo de la pendiente. Allí se ven paredes hechas con la muestra de una tienda o el encerado negro de una clase de Matemáticas; techos de latas claveteadas; puertas que fueron portezuelas de ómnibus [...]. Todo es allí vejez, polilla; todo está a punto de desquiciarse y caer. Es una ciudad movediza compuesta de ruinas de ruinas. Al fin de la barriada está lo que queda de la antigua Arganzuela, un llano irregular, limitado de la parte de Madrid por lavaderos, y de la parte del campo por el arroyo propiamente dicho. Éste precipita sus aguas blanquecinas entre collados de tierra que parecen montones de escombros y vertederos de derribos (La desheredada, 1992: 107).

Luego se acerca a la línea de circunvalación que atraviesa esta soledad. No muy lejos está la estación de La Pulgas (o de las Delicias), «la cual se reconoce, escribe el narrador de Misericordia, desde abajo por la mancha de carbón en el suelo, las empalizadas de cerramiento de vía [...]. Junto a la estación [...], un arroyo de aguas de alcantarilla, negras como tinta, baja por un cauce abierto en los taludes [...], corre a fecundar las huertas antes de verterse en el río» (Misericordia, 1951: 241). Desde allí, prosigue el narrador de La desheredada, «se ven las altas chimeneas de los ventrudos gasómetros de la fábrica 
cercana; pero apenas se ve Madrid. Hay un recodo matizado de verde por dos o tres huertecillas de coles, el cual sirve de unión entre la plaza de las Peñuelas y la Arganzuela» (La desheredada, 1992: 108)

Nótese que Nazarín, antes de su salida evangélica, vive en la calle de las Amazonas, cerca de la puerta de Toledo no muy lejos de la Casa de dormir de la calle Mira el Río.

Las andanzas de Benina y de Manuel (el personaje de La Busca y de Mala Hierba) son mucho más complicadas y me limito a seguir los recorridos que mejor pueden mostrar las varias facetas de aquellos miserables barrios.

Benina vive algún tiempo en la Parada de Santa Casilada, de la que se hablará en el apartado titulado «Casas de dormir, Corralas, Paradas» y a partir de allí recorre los barrios del Sur, siguiendo al moro ciego o andando en busca del él.

Un día, siguiendo las huellas del mendigo, llega hasta el Puente de Toledo. El narrador relata su recorrido:

A la entrada del Puente, dirigióse Benina por la calzada en declive que a mano derecha conduce al arrabal llamado de Las cambroneras, a la margen izquierda del Manzanares. [...] El sitio es pintoresco, ventilado y casi puede decirse alegre, porque desde él se dominan las verdes márgenes del río, los lavaderos y sus tenderijos de trapos de mil colores. Hacia poniente se distingue la sierra, y a la margen opuesta del río los cementerios de San Isidro y San Justo [...]. Al descender pausadamente hacia la explanada, vio la mendiga dos burros [...] y junto a ellos grupos de gitanos tomando el sol. [...]. En los animados corrillos todo era risas, chacota, correr de aquí para allá. [...] Los chiquillos, vestidos de harapos, daban volteretas, y sólo los asnos se mantenían graves y reflexivos (Misericordia, 1951: 236-237)

Otro día, desde la ronda de Toledo, bajan Benina y el moro Almudena hacia el Manzanares.

El marroquí, conocedor de aquel terreno, guió hacia la fábrica del gas, dejándose llevar por su amiga cogido del brazo. Por angostas veredas pasaron al paseo de las Acacias [...]. Y se precipitaron por un sendero empinadísimo [...] Llegaron por fin, a un sitio más abajo que el paseo, suelo quebrado, lleno de escorias que parecen lavas de un volcán [...]; delante tenían techos de viviendas pobres a nivel más bajo que sus pies. En las revueltas de aquella hondonada se distinguían chozas míseras, y a lo lejos, oprimida entre las moles del Asilo de Santa Cristina y el taller de Sierra Mecánica, la barriada de las Injurias, donde hormiguean familias indigentes. (Ibid., 209-210).

¡El barrio de las Injurias! Se situaba entre el paseo de las Acacias y el de Yeserías, cerca de Pirámides. Las Injurias es una hondonada muy profunda donde vivían hacinadas muchas familias miserables. Para conocerlo, mejor es darle la palabra al narrador de Mala Hierba: 
[En 1904] el barrio de la Injurias se despoblaba, iban saliendo sus habitantes hacia Madrid... Era gente astrosa: algunos, traperos; otros, mendigos; otros, muertos de hambre; casi todos de facha repulsiva. Era una basura humana, envuelta en guiñapos, entumecida por el frío y la humedad que vomitaba aquel barrio infecto. Era la herpe, la lacra, el color amarillo de la terciana, el párpado retraído, todos los estigmas de la enfermedad y la miseria (Mala Hierba, 1904).

De paso se notará el frío rigor de legista de Baroja que contrasta con el calor humano que se desprende de las palabras de Galdós y, en otras formas, como veremos, de doña Emilia.

Para terminar esta abreviada expedición literaria por la geografía natural y humana de aquellos barrios de la miseria del Sur de Madrid, sigamos las sinuosas andanzas por esas tierras de Manuel y su pandilla, la de los Piratas.

Salieron los Piratas de la Casa del Cabrero, bajaron a una hondonada [...] y desembocaron en el Paseo de Yeserías. Se acercaron al depósito de cadáveres, un pabellón blanco próximo al río. [...] Siguieron andando por la orilla del Manzanares, entre los pinos torcidos de la Dehesa. [...] Al final de la Dehesa de la Arganzuela, frente a un solar espacioso y grande, [...] se detuvo la cuadrilla a contemplar el solar, cuya área extensa la ocupaban carros de riego, barrederas mecánicas, bombas de extraer pozos negros, montones de escobas y otra porción de menesteres y utensilios de la limpieza urbana.

Se veía Madrid envuelto en una nube de polvo, con sus casas amarillentas. Las altas vidrieras relucían a la luz del sol poniente. Del Paseo del Canal, atravesando un campo de rastrojo, entraron todos por una callejuela en la plaza de las Peñuelas; luego, por otra calle en cuesta, subieron al Paseo de las Acacias (La Busca, 1972: 77-78)

Manuel sigue solo, deseando llegar a la Corrala, a la Casa de dormir de Mira el Río. Al llegar frente a la escalera de la calle del Águila se sienta a descansar en el Campillo de Gil Imón. «Veíase desde allá arriba el campo amarillento [...]. Asomaban por encima de las tapias las torrecitas del cementerio de San Isidro». Llega por fin a la casa del tío Rilo, del arroyo de Embajadores ( $\mathrm{La}$ Busca, 1972: 79).

Esta casa de vecindad, casa de dormir, también llamada la Corrala, el Corralón, la Piltra, la casa del arroyo de Embajadores, (La Busca, 1972: 81) o la casa de Mira el Río es la que han visitado Guillermina y Jacinta. Es pues el oportuno momentos para explorar a partir de las tres novelas, Fortunata y Jacinta, Misericordia y La Busca esas casas de la hacinada miseria. 


\section{CASAS DE DORMIR, CORRALAS O PARADAS}

Se parecen todas, no las hay de una estrella o dos y si en la de la calle de la Goutte d'Or se habla francés, un recio francés popular, no hay en ella más espacio ni menos ruido ni menos suciedad ni peores malos olores que en las dos que vamos a visitar, un poco más arriba de la ronda de Toledo, cerca del arroyo de Embajadores la una, próxima a la glorieta de Embajadores la otra, como se ve en nuestro mapa artesanal. La primera, la visitamos siguiendo a Guillermina y Jacinta y acompañando a Manuel; en la segunda, llamada de Santa Casilda, se alojan un tiempo Benina y el mismo Manuel.

Las dos las conoce bien Galdós que las escudriñó «acompañado de un policía», según confiesa en el Prólogo a Misericordia. Es indudable que Baroja, por la minuciosa descripción que hace de ellas, particularmente de la que llamaremos de Mira el Río, pasó por ellas una despiadada mirada escrutadora.

A unos quince años de distancia, es la misma corrala de Mira el Río la que visitan Jacinta y Guillermina, acompanadas por el narrador de la novela y la que describe con pelos y señales el doctor Baroja, olvidándose de su personaje que ahí está alojado. El edificio está construido en torno a dos patios, separados por un «corredor», dice el narrador galdosiano, o por un «pasillo lleno de inmundicias», escribe Baroja. El segundo mucho más feo, sucio y triste que el anterior.

Comparado con el segundo, el primero tenía algo de aristocrático y podría pasar por albergue de familias distinguidas. Entre uno y otro patio, que pertenecían a un mismo dueño [...] había un escalón social, la distancia entre lo que se llama capas. Las viviendas en aquella segunda capa eran más estrechas y miserables que en la primera; el revoco se caía a pedazos [...], las maderas más despintadas y roñosas, el aire más viciado, el vaho que salía por puertas y ventanas más espeso y repugnante. Jacinta que había visitado algunas casas de corredor, no había visto ninguna tan tétrica y maloliente» (Fortunata, 1993: 186)

La narración descriptiva del recorrido de las dos señoras cubre diez páginas de la novela y relata varias escenas o secuencias más o menos desarrolladas, como la que ocurre en la mansión de Ido del sagrario (Ibid., 188-196). La relación de Baroja se explaya en un poco más de seis páginas. Objetivamente los dos textos presentan la misma realidad observada: los dos patios, las mismas escaleras, las mismas galerías, los mismos cuartuchos y del conjunto sobresale todo el campo semántico de la miseria, de la degradación material de un medio ambiente de espacios confinados y de la suma pobreza de unos seres humanos, algunos de los cuales intentan sobrevivir con dignidad dedicándose a precarias actividades (de carpintería, zapatería, de costura, de pintura de 
cartas de luto, etc.), otros diluyen la mala suerte en el alcohol, muchos parecen haber abdicado, renunciado, aceptando sin conciencia su triste situación. «En la mayor parte de los cuartos y chiribitiles de la Corrala, saltaba a los ojos la miseria resignada y perezosa, unida al empobrecimiento orgánico y al empobrecimiento moral» (La Busca, 1972: 84).

Un parrafito le basta a Baroja para sintetizar la realidad de esa concentración humana, previamente descrita con rigor de sociólogo:

Era la Corrala un mundo en pequeño, agitado y febril, que bullía como una gusanera. Allí se trabajaba, se holgaba, se bebía, se ayunaba, se moría de hambre; allí se construían muebles, se falsificaban antigüedades, se zurcían bordados antiguos, se fabricaban buñuelos, se componían porcelanas rotas, se concertaban robos, se prostituían mujeres (La Busca, 1972: 86).

Para los que vienen de fuera y se asoman a aquellos espacios todos los sentidos están agredidos por lo que se ve, lo que se oye, lo que se toca, lo que se huele. Fuerte y amplio es sobre este punto en los trozos de las dos novelas el abanico adjetival, repetido, de las sensaciones desagradables: negruzco, sucio, pringoso, fétido, nauseabuno, maloliente, pestilente, etc.

Pero si la percepción de esta miserable realidad por los dos novelistas es objetivamente igual, su representación literaria es diferente y deja traslucir, tal vez, dos «temperamentos» distintos. Primero está bien claro que el texto de Baroja es la relación minuciosa de una escrupulosa encuesta, es, sin determinación de tiempo, un sumario que no deja paso a ninguna escena, es decir la representación del presente en su pasado. Se trata pues no de una narración sino de una relación distanciada que tiene la precisión, incluso colorista, de una memoria de sociólogo o de médico higienista de positivista moral. El texto de Galdós es la narración de una visita que se desarrolla una tarde precisa y cuyo narrador descubre la realidad que se ofrece al mismo tiempo que las dos mujeres en un presente de immeditez y de espontaneidad; y ante el espectáculo que se ofrece se combinan las miradas, las impresiones y las sensaciones de los tres lo cual humaniza la percepción y abre paso a la expresión del sentimiento (de que carece la relación del autor de La Busca). Lástima, compasión, sentires, perceptibles siempre y notables con más fuerza, no ante la situación de la infancia sino de unos niños de carne y huesos con, en algunos casos, más huesos que carne. ¡Unas niñas que imitan con barro, palitos y cuerdas el secadero de la Injurias, el barrio de abajo y el más podrido del entorno!: ¡insólito símbolo! (Fortunata, 1993: 184). En los patios descritos por Baroja no hay niños, sólo unos adolescentes que juegan a los toros...

La descripción de la otra corrala, llamada «Parada de Santa Casilda», situada un poco más abajo de la primera «no lejos del punto en que Mesón de 
Paredes desemboca en la ronda de Toledo» (Misericordia, 1951: 51) es mucho más breve en las dos novelas. Ahí se alojan algún tiempo el moro Almudena y Manuel. Es una «vasta colmena de viviendas baratas alineadas en corredores sobrepuestos. Éntrase a ella por un patio o corralón largo y estrecho, lleno de montones de basura, residuos, despojos y desperdicios de todo lo humano» (Ibid., 51-52). Manuel alquila allí, por ocho reales, «un cuartucho con una cama, una silla rota de paja y una estera colgada del techo que hace de puerta. [...] Desde la ventana del cuartucho de Manuel se veían tres depósitos, panzudos, rojos, de la Fábrica del Gas [...] y alrededor el Rastro; a un lado vertederos ennegrecidos por el carbón y las escorias [no muy lejos, más abajo, está la Estación de La Pulgas]; más lejos se extendía el paisaje árido, y sus lomas calvas, amarillentas» (Mala Hierba, 1974: 139-140). Y por todo el entorno un enredo de callejas y senderos.

\section{ESAS CALLEJAS}

Una red de calles, callejas, callejuelas, caminos y senderos cuadricula aquellos barrios del Sur; por ella corre el flujo humano que sale de aquellos centros del «comunismo del hambre» que son las Casas de Dormir (La Busca, 1972: 84) y de otras oscuras guaridas... Allí se codean mujeres en busca de sustento, menestrales, pordioseros, vendedores de baratijas, etc, etc.; pobreza maleante y pobreza honrada, todo mezclado.

Un buen ejemplo de pura pobreza honrada lo ofrece doña Emilia al describir la calle de los Castros, donde vive Amparo. Esta evocación (o visión) es también un sumario, una reconstrucción a partir, tal vez, de varias visitas, cuyas imágenes se superponen y se mezclan con reminiscencias de lecturas que se deslizan en intertextualidad; carece pues de ese efecto de realidad que sólo puede dar el contacto directo e inmediato (ficticio o no) en un momento preciso (como en el caso de la visita de Guillermina y Jacinta).

El barrio de Amparo era de gente pobre; abundaban en él las cigarreras, pescadores y pescantinas [...]. Sobre el parapeto del camino real que cae al mar, estaban siempre de codos algunos marineros, con gruesos zuecos de palo, faja de lana roja, gorro catalán; sus rostros curtidos, su sotabarba poblada y recia, su mirar franco, decían a las claras la libertad y rudeza de la vida marítima; a pocos pasos de este grupo, que rara vez faltaba aquí, se instalaba en la confluencia de la alameda y la cuesta, el mercadillo... (La Tribuna, 2002: 219. Lo enfatizado es marca de que se trata de un sumario)

No es que no esté exacta la pintura, pero estamos más cerca de la bonachona estética de los tópico costumbristas (¡la raída imagen de la faja de lana!) 
que de la estética de la verdad iniciada por La desheredada en la estela de L'Assommoir.

«Vivía el barrio entero en la calle, por poco que el tiempo estuviese apacible» (enfatizo la marca del sumario). Y sigue un animado y luminoso cuadro de una plasticidad digna de un Sorolla; una distributiva descripción encaminada a mostrar que aquí todo se hace a la vista de todos en alegre promiscuidad y que la característica de la vida del pueblo es una natural espontaneidad, de tú a tú. «Todas las excrecencias de la vida, los prosaicos menesteres que en lo barrios opulentos se cumplen a sombra de tejados, salían allí a luz y a vistas del público» (Ibid., 220-221). Aquí, naturalmente y sin daño alguno se cumple el principio de Taine (o la ley de Darwin) de adaptación al medio: «Tampoco faltaban comercios que, acatando la ley que obliga a los organismos a adpatarse al medio ambiente, se acomodaban a la pobreza de la barriada» (Ibid., 221-222). «Todo se compraba fiado [...]. Reinaba en el barrio cierta confianza, una especie de compadrazgo perpetuo, un comunismo amigable» (Ibid.).

Todo pues, en este espacio popular está a tono con la enseñanza de los Evangelios y ante tan honrada pobreza casi se le desliza a uno en la mente que «afortunados los pobres» $\mathrm{y}$ «que los últimos serán los primeros». Es verdad probalemente que la pobreza integrada de una ciudad provincial no es la sórdida miseria tirada a los barrios del Sur madrileño, pero no puede negarse que la condesa ennoblece a los pobres según el tradicional criterio cristiano, es su derecho y muy respetable, pero en esta parte de la novela (no en otras y aun aquí cuando habla de los niños, como veremos en el apartado oporuno), no está a tono doña Emilia con la estética de la verdad, esta cuestión palpitante que por aquellos mismos años ella misma está asimilando.

Efectivamente es la primera en representar detalladamente y con toda la fuerza de la verdad las duras y a veces inhumanas condiciones de trababajo en la Fábrica de Tabacos de Marineda.

\section{TALLERES Y FÁBRICAS}

Cabe recordar, sin embargo, que hay antecedentes que a la Pardo Bazán le han abierto el camino, si no de la imitación, por lo menos de una posibilidad de representación de un aspecto no tomado en cuenta por la litertura: el mundo del trabajo. Es muy posible que la pintura del durísimo trabajo de Goujet en la fragua de la Goutte-d'Or haya incitado a Galdós a introducir en La desheredada la descripción del taller de soga cerca del barrio de las Peñuelas, en el que trabaja Mariano, el hermano de Isidora. 
Ésta y su tia, la Sanguijuelera, visitan el taller, que está situado en medio de «pequeñas viviendas numeradas, o sea, de casa celular para pobres» ( $\mathrm{L} a$ desheredada, 1992: 47), que podría ser la Parada de Santa Casilda.

Atrevesaron un antro [...]. Halláronse en extraño local de techo tan bajo que sin dificultad cualquier persona de mediana estatura lo tocaba con la mano [...]. Era como un gran túnel, del cual no se distinguía sino la parte escasamente iluminada por la boca. [...]. En la parte clara de tan extraño local había grandes fardos de cáñamo en rama, rollos de sogas blancas [...] y en el suelo y en los bultos todos una pelusa áspera, filamentos mil que después de flotar por el aire [...] iban a posarse aquí y allá, sobre la ropa, el cabello y la nariz de las personas (La desheredada, 1992: 47).

Tal es el medio ambiente: estrechez, oscuridad, falta de higiene. Después se evoca «el trabajo del día»:

El cáñamo se retorcía con áspero gemir, enroscándose lentamente sobre sí mismo. Los hilos montaban unos sobre otros, quejándose de la torsión violenta, y en toda su magnitud rectilínea había un extremecimiento [sic] de cosa dolorida y martirizada que irritaba los nervios del espectador, cual si también, al través de las carnes, los conductores de la sensibilidad estuviesen sometidos a una torción semejante (Ibid., 47).

No se evoca al principio al hombre; sólo padece la materia y sus dolorosas contorsiones simbolizan el sufrimiento del obrero; y el caso es que el obrero a quien buscan las dos mujeres es Mariano, un chico de trece años.

Minuciosa, sin concesión al decoro (de su clase), «verista», naturalista, en suma, según la línea de Zola, es la descripción realmente del natural, directa, quiero decir escenificada, del trabajo en la Fábrica de Tabacos de Marineda. Además es una descripción completa; siguiendo en general a la protagonista, Amparo, el narrador (la narradora) pasa de un taller a otro, el taller de cigarrillos, el de desvenado, el de picadura, etc. para dar finalmente una visión total de la fábrica. Pero lo más novedoso es que la novelista, émula de Zola y del Galdós de La desheredada, no se arredra por nada y pinta sin pestañear las más crudas escenas de aquellas inhumanas faenas.

En el taller de desvenado daba frío ver, agazapadas sobre las negras baldosas y bajo sombría bóveda [...] y algo semejante a una cripta sepulcral, muchas mujeres, viejas la mayor parte, hundidas hasta la cintura en montones de hojas de tabaco, que revolvían con sus manos trémulas, separando la vena de la hoja. Otras empujaban enormes panes de prensado, del tamaño y forma de una rueda de molino [...]. La atmósfera era a la vez espesa y glacial ( $\mathrm{La}$ Tribuna, 2002: 166)

Peores son las condiciones de trabajo en el taller de picadura. 
Dentro de una habitación caldeada, pero negruzca ya por todas partes, y donde se filtraba luz a través de los vidrios sucios de alta ventana [notése la analogía con el taller de soga de La desheredada], vieron las dos muchachas hasta veinte hombres vestidos con zaragüelles de lienzo muy amplios [...] y saltando sin cesar.[...] Cada dos hombres tenían [sic] ante sí una mesa o tablero, y mientras el uno saltando con rapidez, subía y bajaba la cuchilla picando la hoja, el otro, con los brazos enterrados en el tabaco, lo revolvía para que el ya picado fuese deslizándose y quedase sólo en la mesa el entero, operación que requería gran agilidad y tino, porque era fácil que, al caer la cuchilla, segase los dedos o la mano que encontrara a su alcance. Como se trabajaba a destajo, los picadores no se daban punto de reposo: corría el sudor de todos los poros de su miserable cuerpo, y la ligereza del traje y violencia de las actitudes patentizaban la delgadez de sus miembros, el hundimiento del jadeante esternón, la pobreza de las garrosas canillas, el térreo color de las consumidas carnes (Ibid., 168).

Uno de esos picadores es Chinto, un mozuelo de poca más edad que el Mariano de las Peñuelas. Los niños de la miseria salen de las calles o de los patios de las corralas para emplearse, tal vez en el mejor caso, en trabajos embrutecedores, ya penosos para adultos.

\section{LOS NIÑOS DE LA MISERIA}

En los barrios urbanos de la miseria, los acostumbrados espacios de vida de los niños son las callejas sucias, las plazuelas ruinosas o los patios polvorientos o fangosos de las corralas. De esta realidad dan testimonio, en forma literaria, es decir con el calor más o menos poético de la percepción personal, La desheredada, La Tribuna, Fortunata y Jacinta.

Sabemos que al llegar a la calle de Moratines, en el barrio de las Peñuelas, el narrador de las andanzas de Isidora abandona un momento a su personaje para observar el entorno. Queda largo momento contemplando la «chiquillería formidable» que de golpe invade la plaza de las Peñuelas.

Había en las filas renacuajos de dos pies de alto con las patas en curva y la cara mocosa, que blasfemaban como carreteros; [...] había piernas blancas desnudas asomándose a las ventanas de un pantalón que a pedazos se caía; había zancas negras, esbeltas cinturas ceñidas por sucia cuerda [...]; chaquetones que fueron de abuelos, y calzones que fueron mangas; [...] gorras peludas que fueron, ! ay !, manguitos de elegantes damas (La desheredada, 1992: 100).

Los cráneos achatados, los pómulos cubiertos de granulaciones y el pelo ralo ponían una máscara de antipatía sobre las siempre interesantes facciones de la niñez (Ibid., 98) 
Esta abigarrada multiturba, cómicamente ataviada, está jugando a la guerra. El que contempla este espectáculo, el narrador de la novela, no consigue mantener la impersonalidad del canon naturalista: se mezclan en su narración descripciones y reflexiones, y se ensancha la observación, tomando valor metonímico, hasta la generalización.

Eran [los chicos] la alegría y el estorbo del barrio, estímulo y apuro de sus padres, desertores los más de la escuela, un plantel del que saldrían quizás hombres de provecho y, sin duda, vagos y criminales (Ibid., 99).

La animación principal de aquel cuadro era un centellear de ojos y un relampaguear de alegrías divertidísimo. Con aquel lenguaje mudo decía claramente el infantil ejército [...]: «Somos granujas; no somos aún la Humanidad, pero sí un croquis de ella. España, somos tus polluelos y, cansados de jugar a los toros, jugamos a la guerra civil» (Ibid., 100)

Dicho sea de paso, el último párrafo citado muestra que en La desheredada quedan resabios de la anterior novela de tesis; y a mi modo de ver no para mal.

Más contrastada aún es la visión literaria que da la narradora de La tribuna de «la tribu», «pollada», «hormiguero» de chiquillos que invaden la calle de Los Castros. Contrastada porque se yuxtapone el bondadoso punto de vista costumbrista de donde procede el siguiente vocabulario: «ángeles», «bonitos como querubines», «ágiles como micos o como ardillas», con las osadías de las alusiones a «los mocos», a «las pústulas de la viruela» o a «las ronchas del sarampión», y con recortadas viñetas naturalistas, ya entrevistas algunas en otra novela y que supera en efecto repulsivo a cuanto pudo atreverse Zola. «Los había patizambos, que corrián como asustados palmípedos», es, en plural, la amplificación de la estampa del «renacuajo»dibujada por Galdós y citada atrás (si será un guiño para decirle al autor de La desheredada: «visto y entendido»). Y, colmo de repulsión, «los había [siempre en plural] horribles y encogidos como los fetos que se conservan en aguardiente» (La tribuna, 2002: 219). Verismo, sí, ma non tropo.

De más equilibrado realismo es la visión de los niños que llenan los patios y los corredores de la Corrala de Mira el Río, tal vez porque con los años el arte de la representación ha madurado; también, como los visitantes andan buscando entre toda la chiquillería al Pituso, el hijo de Fortunata, puede que las miradas permanezcan focalizadas en lo que ven y no se extravíen en comentarios o extrapolaciones... seudo-artísticas. Ahí, como en todas partes, juegan los niños y, como es natural, con lo que tienen a mano, el barro, el polvo o la caja de betún rapiñada en algún rincón; hasta, ahí está «el que va a la escuela con su cartera de estudio»(Fortunata, 1993: 182). 
De todas formas, más allá de lo que plasman los novelistas, según su «conciencia y hablidad», como dice Clarín, la visión que dan en conjunto de la situación de la infancia en los barrios de la miseria o de la pobreza es un documento vivo sobre un aspecto de la realidad histórica.

Hasta se podría concluir que estas novelas en su conjunto constituyen un documento vivo sobre la total realidad de los barrios de la miseria en aquella época y si estuviera permitido extrapolar, podría decirse sobre los espacios de la miseria, cualquiera sea la época.

\section{ÚLTIMAS PUNTUALIZACIONES LITERARIAS PARA CONCLUIR}

A pesar de las malas lecturas a que ha dado lugar el naturalismo literario, debidas en gran parte a la discutible y tan discutida teoría elaborada por el mismo Zola, la corriente naturalista, iniciada por los Goncourt y consagrada por las novelas artísticas del autor de L'Assommoir, se ha derramado por toda Europa como dice este último en su carta a Albert Savine a propósito de $L a$ papallona (Bonet, 2010) y ha dado vida a una nueva estética, la estética de la verdad.

A partir de entonces, «de toda realidad se puede hacer asunto de novela», escribe Clarín que acto seguido precisa, "pero no porque se haya descubierto que la novela puede ser prosaica, sino porque en toda realidad se puede ver poesía» (Alas, 1887).

Hasta la segunda mitad del siglo XIX, la buena literatura ha ignorado el sudor del duro trabajo y los malos olores de la pobreza. E incluso después, siguen activos los partidarios de la estética de lo bello que rechaza lo vulgar y lo feo por indigno del arte. Por ejemplo, al gran novelista Valera no le parece de buen tono que un autor vaya a visitar los espacios reservados del cuarto estado para hacer de lo visto y observado materia novelable. Su estética tolera lo vulgar y lo feo con tal que realcen lo bello o que sea objeto de lo cómico; para él, y lo dice, no son concebibles Maritornes y Sancho sin Don Quijote. No está muy lejos la concepción de Valera de la tradicional jerarquía de los estilos, tan bien explicada par Auerbach, según la cual para lo grande y lo noble (lo bello), la epopeya o la tragedia, para lo vulgar y lo feo (el villano, el campesino, el proletario, etc.), la comedia.

La novela naturalista de la segunda mitad del siglo XIX en Francia, en Europa, en España, gracias al total ensanchamiento temático y al rigor puesto en la fidelidad de la representación, rompe esta jerarquía de los estilos.

Amparo es una mujer del pueblo, una cigarrera, y es la protagonista de La Tribuna; es verdad que sus dotes, sus virtudes y su autenticidad hacen de ella una heroína, estatuto literario poco apreciado por la estética naturalista. 
La Sanguijuelera, la tía de Isidora, a pesar de su lenguaje arrabalero, no es un personaje cómico, es una mujer del pueblo con sus ideas conservadoras, su recta moral; es un personaje tan digno como cualquier burgués, más o menos fariseo, del centro de Madrid. Los obreros que invaden el Boulevard no mueven a risa ni siquiera cuando sueltan extrañas palabras de su vocabulario arrastradas por específica sintaxis; al contrario, son vistos como los únicos en Vetusta que gozan de la sana satisfacción de cumplir con su trabajo.

Ya que se habla de lenguaje, así de paso, es oportuno recordar que falta aquí un análisis del que se han forjado los olvidados de los barrios del pueblo bajo. Uno de los grandes aciertos del narrador de L'Assommoir es hablar él mismo el lenguaje de los personajes que, entre entrecomillado e indirecto, es el de toda la novela. Así pues, unidad de lenguaje en unidad de espacio. Esa guasa arrabalera que lo llena todo contribuye a hacer de L'Assommoir un modelo artístico y tiene un encanto capaz de impresionar a Mallarmé.

Por ser resultado de una pensada y decidida estética de la verdad, la novela realista del siglo XIX, del gran realismo, además de obra de arte vale como documento vivo, animado por la conciencia y la habilidad del artista (Lissorgues, 2002). Gracias a ella siguen viviendo las imágenes animadas, con sus voces, sus colores, sus olores, de los olvidados barrios de la miseria.

\section{BIBLIOGRAFÍA}

Alas, Leopoldo, Clarín, «La desheredada, Primera parte», Los Lunes de El Imparcial, 9 de mayo de 1881, en Adolfo Sotelo, 1991, 88-89.

Alas, Leopoldo, Clarín, La Regenta [1884-1885], edición de Gonzalo Sobejano, Madrid, Clásicos Castalia, 1981.

ALAS, Leopoldo, Clarín, «Los pazos de Ulloa», La Ilustración Ibérica, 5 de febrero de 1887, en Obras completas, tomo VII, Artículos (1882-1890), Oviedo, Ediciones Nobel, 2004, 611.

AuERBACH, Eric, Mimésis. La représentation de la réalité dans la littérature occidentale [1946], Paris, Gallimard, 1968.

Ayala, María Ángeles, «Introducción» a Eusebio Blasco, Madrid por dentro y por fuera, Madrid, «Biblioteca Nueva»/Universidad de Alicante, 2008, pp. 11-64.

Baroja, Pío, La Busca [1904], Madrid, Caro Ragio, 1973.

Baroja, Pío, Mala Hierba, [1904], Madrid, Caro Ragio, 1974.

BESER, Sergio, Leopoldo Alas: Teoría y crítica de la literatura española, Barcelona, Editorial Laia, 1972.

BLASCO, Eusebio, [1873], Madrid por dentro y por fuera, edición de María Ángeles Ayala, Madrid, «Biblioteca Nueva»/Universidad de Alicante, 2008. 
BONET, Laureano, «La Papallona de Narcis Oller: los murmullos y las luces de Barcelona», traducción al español del Proleg «La Papallona de Narcis Oller: els murmuris, les llums i les ombres de Barcelona», La Papallona, Barcelona, Cosselania Edicions, 2010.

DíAz LAGE, Santiago, «Dos versiones de La cigarrera, texto olvidado de Emilia Pardo Bazán», La Tribuna, n 004, 2006, pp. 356-384.

FAus, Pilar, Emilia Pardo Bazán, su época, su vida, sus obras, La Coruña, Fundación Pedro Barrié de la Maza, 2003.

LISSORGUES, Yvan, «El modelo teórico del Naturalismo. Ciencia positiva y literatura. Propuestas estéticas y temáticas. El debate sobre el Naturalismo y el Simbolismo», Historia de la literatura española (Director Víctor García de la Concha), Siglo XIX (II) (Coordinador Leonardo Romero Tobar), Madrid, Espasa, 1998, pp. 19-31.

LISSORGUES, Yvan, «El hombre y la sociedad contemporánea como materia novelada», Guadalupe Gómez-Ferrer Morant (coord.), Historia de España Menéndez Pidal (José María Jover Zamora, director), Tomo XXXVI, La época de la Restauración (1875-1902), Madrid, Espasa, 1999, pp. 419-464.

PAGÉS, Alain, Guide Zola, Paris, Ellipses, 2002.

PALACIO VALDÉS, Armando, «Viaje a la Riosa», capítulo XII de La espuma [1890], Edición de Guadalupe Gómez-Ferrer Morant, Madrid, Clásicos Castalia, 1990.

PARdo BAZÁn, Emilia, La Tribuna [1883], Edición de Marisa Sotelo, Madrid, Alianza Editorial, 2002.

PÉREz GALDÓs, Benito, La desheredada [1881], Edición de Enrique Miralles, Barcelona, Planeta, 1992.

PÉRez Galdós, Benito, Fortunata y Jacinta, Edición de Adolfo Sotelo Vázquez y Marisa Sotelo Vázquez, Barcelona, Planeta, 1993.

PÉrez Galdós, Benito, Misericordia [1897], Paris, Nelson, 1951, con «Prefacio del autor escrito especialmente para esta edición», pp. 7-9, y una «Introducción» de Alfred Morel-Fatio, pp. 11-16.

SAILlard, Simone, «Les textes traduits de Zola: bilan et perspectives», Simone Saillard et Adolfo Sotelo Vázquez (eds.), Zola y España, Barcelona, Universidad de Barcelona, 1997, pp. 99-115.

SOLDA, Pierre, «Émile Zola et le parti pris du nauséabond», Les Cahiers Naturalistes, n 71,1997 , pp. 175-190.

Sotelo VÁzQUez, Adolfo, Leopoldo Alas. Galdós novelista, Barcelona, PPU, 1991.

Sotelo VÁzQUez, Marisa, La cigarrera revolucionaria. La Tribuna de Emilia Pardo Bazán, Universidad de Minnesota, «Ediciones del Oro», 2010.

VALERA, Juan, El arte de la novela, Edición, prólogo, y notas de Adolfo Sotelo Vázquez, Barcelona, Editorial Lumen, 1996.

ZoLA, Émile, L'Assommoir [1877], Paris, Fasquelle, 1967.

Anales, 24, 2012, pp. 83-109 
ZoLA, Émile, «Carta de Émile Zola à M. Savine» [15 octobre 1885], a propósito de Le Papillon, Bonet, 2010.

ZOLA, Émile, Le roman expérimental [1879-1880], Edition, chronologie et préface de Aimé Guedj, Paris, Garnier- Flammarion, 1971.

ZolA, Émile, El naturalismo, Traducción de Jaume Fuster, Edición, introducción y notas de Laureano Bonet, Barcelona, Península, 1989.

Fecha de recepción: 4-12-2011

Fecha de aceptación: 30-3-2012 